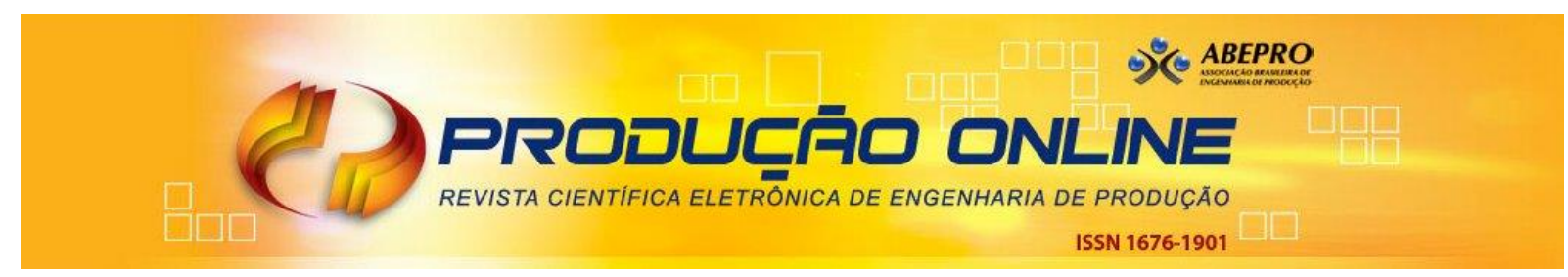

\title{
DIAGNÓSTICO DO NÍVEL DE SUSTENTABILIDADE EM COMUNIDADE DO GEOPARK ARARIPE DA UNESCO
}

\section{DIAGNOSIS OF THE SUSTAINABILITY LEVEL IN UNESCO ARARIPE GEOPARK'S COMMUNITY}

\author{
Ana Karine Gomes Duarte* E-mail: karine.duarte@urca.br \\ Francisca Jeanne Sidrim de Figueiredo Mendonça* E-mail: \\ jeanne.sidrim@urca.br \\ Nájila Rejanne Alencar Julião Cabral ${ }^{\star *}$ E-mail: najila@ifce.edu.br \\ Bruna Stephany Coelho de Souza*E-mail: bruna.stephany@urca.br \\ *Universidade Regional do Cariri (URCA), Crato, CE \\ **Instituto Federal do Ceará (IFCE), Fortaleza, CE
}

\begin{abstract}
Resumo: No cenário atual as práticas relacionadas à sustentabilidade estão sendo cada vez mais indispensáveis para gerir qualquer negócio e melhorar qualidade de vida. Visando a necessidade de uma agenda ambiental comprometida com o desenvolvimento econômico e a manutenção da qualidade ambiental foram estipulados os Objetivos do Desenvolvimento Sustentável (ODS) pela Organização das Nações Unidas (ONU). Este trabalho mostra a realidade em 5 comunidades interioranas em atendimento aos ODS. Trata-se de um estudo de caso no entorno dos geossítios do Geopark Araripe da UNESCO, identificando gargalos e avanços que merecem melhor visibilidade para que uma vida sustentável seja alcançada. A partir do estudo ampliado da relação dos 17 Objetivos do Desenvolvimento Sustentável com as práticas vivenciadas pelas comunidades, foram realizadas entrevistas estruturadas, no período de maio a dezembro de 2020, a fim de se obter um diagnóstico do comprometimento destas comunidades com as metas dos ODS. Realizou-se análise SWOT para identificação dos pontos fortes e fracos dos geossítios, no sentido de subsidiar ações futuras de promoção ao desenvolvimento sustentável ao dia a dia destas comunidades.
\end{abstract}

Palavras-chave: Sustentabilidade. Geossítios. Geoparque. Objetivos do Desenvolvimento Sustentável.

Abstract: Sustainability practices are becoming increasingly imperative to manage any business or quality of life in the global society. This paper addresses this need for change and the United Nations (UN) goals for sustainable development, showing the reality faced by communities via a case study surrounding the UNESCO Araripe Geopark geosites. The study was done to identify points that deserve further visibility to achieve a truly sustainable life. A comprehensive review of the 17 Sustainable Development Goals was carried out. The goals that best adapted to the studied region were chosen, and structured interviews were conducted within the community to obtain an accurate and authentic diagnosis, directed to the strong and weak points of the geosites. This approach allowed for a thorough understanding of the possibilities and threats to incorporating suitable sustainable practices tailored to the studied region's reality.

Keywords: Sustainability. Geosites. Geoparks. Sustainable Development Goals. 


\section{INTRODUÇÃO}

O conceito desenvolvimento sustentável é algo que vêm sendo discutido por especialistas e organizações há muito tempo. O termo surgiu primeiramente no relatório Nosso Futuro Comum (1987) da Organização das Nações Unidas (ONU), que define desenvolvimento sustentável como: "o desenvolvimento que procura satisfazer as necessidades da geração atual, sem comprometer a capacidade das gerações futuras de satisfazerem as suas próprias necessidades" (UN, 1987).

Este desenvolvimento deverá ser reproduzido com a participação dos indivíduos e a coletividade, tendo como base a livre autodeterminação dos povos e o respeito à sua identidade cultural (CHIPINDO, 2018). Apesar das discussões acerca do conceito de desenvolvimento sustentável, pôde-se estabelecer uma linha comum de discussão, que envolve ideias de eficiência econômica, equidade social e equilíbrio ambiental (VILHAS; QUADROS, 2012).

Em busca de alcançar este caminho de desenvolvimento que envolva as diretrizes econômica, social e ambiental, a ONU em conjunto com chefes de países associados elaboraram um plano de ação para indivíduos e planeta, para trilhar um caminho mais sustentável, econômica e conscientemente, de forma resiliente até o ano de 2030. Esse plano de ação ficou conhecido como Agenda 2030 para o Desenvolvimento Sustentável, que incorpora 17 Objetivos do Desenvolvimento Sustentável (ODS) e 169 metas para consagrar o objetivo final. Autores como Biermann et al (2017) e Menezes (2018) expõem sobre a importância dos ODS no alcance da sustentabilidade em níveis diversos de implementação de políticas públicas. O Brasil alinhou objetivos nacionais aos ODS. Realizou-se esforço de diferentes órgãos que culminou no total de 175 metas nacionais (algumas foram acrescidas para atender as especificidades do país), sendo 76 destas classificadas como de implementação e 99 identificadas como finalísticas (IPEA, 2018).

Os objetivos e metas propostos na Agenda 2030 foram assinados e concordados por todos os países e podem ser aplicados integralmente nessas nações. Levando em conta o contexto dos Geoparques Mundiais da UNESCO, admite-se que os ODS podem ser aplicados em sua totalidade nas comunidades desses territórios. A união comunidade e geoconservação, mostra-se, portanto, um elemento-chave para a gestão de estratégias de conservação natural e apoio à 
proteção do patrimônio local, assim como o desenvolvimento econômico e social (SANTOS; JACOBI, 2017).

O Geopark Araripe, primeiro Geopark das Américas e do hemisfério sul com selo da UNESCO e componente da Rede Global de Geoparques (GGN), foi criado em 2006 e situa-se na região sul do Ceará, no contexto geomorfológico da Chapada do Araripe. O Geopark Araripe possui atualmente 9 (nove) geossítios abertos para visitação e com amplas possibilidades de crescimento (MOURA-FÉ, 2016).

É de suma importância que o Araripe Geopark Mundial da UNESCO possua mais engajamento na Rede Global de Geoparques (GGN) possibilitando melhor inserção social do projeto no Cariri cearense para que haja uma utilização efetiva e o cumprimento dos seus objetivos fundamentais (MOURA-FÉ, 2017a), a saber:

- promover a conservação do patrimônio natural (geodiversidade e biodiversidade) e do patrimônio associado (geo)cultura.

- desenvolvimento socioeconômico sustentável das comunidades locais, a priori, aquelas situadas próximas aos geossítios, através da geoeducação e do geoturismo, objetivando a identificação, aproximação e cogestão desses espaços(conhecer/cuidar/gerir).

O Araripe Geopark Mundial da UNESCO está em busca de alcançar os objetivos anteriormente tratados por meio do apoio de organizações parceiras, para que elas entendam como podem fazer parte desse movimento mundial. Surge deste cenário alguns questionamentos: Que ações podem levar uma comunidade a alcançar uma gestão sustentável? Quais dos objetivos da UNESCO estão de forma empírica sendo vivenciadas em comunidades do interior do Nordeste brasileiro?

O estudo de caso foi realizado em comunidades dos geossítios do Araripe Geopark Mundial da UNESCO. Foram feitas visitas e aplicação de questionário com os moradores desses locais, com isso foi possível coletar dados, fazer análises e obter resultados.

\section{DESENVOLVIMENTO SUSTENTÁVEL}

A preocupação com o meio ambiente e seus impactos causados pela sociedade se deu historicamente a partir da realização da Conferência de Estocolmo, em 1972. Fortaleceu a partir do ano de 1987, com a publicação do relatório "Nosso 
futuro comum" ou também conhecido como "Relatório de Brundtland", por ter sido presidida pelo então primeiro-ministro da Noruega, Gro Harlem Brundtland, que por sua vez elaborou uma conexão entre meio ambiente e ações, ambições e necessidades humanas, conseguindo, então, um olhar atento das grandes nações para este problema até então negligenciado (OLIVEIRA, 2017).

No Relatório Brundtland, além dos problemas socioeconômicos e ecológicos ligados à sociedade, é enfatizado a relação entre economia, tecnologia, sociedade e política, ampliando uma postura ética responsável adequada para a preservação das gerações futuras e para maior aproveitamento da atual (MOURA; BARRETO FILHO, 2017).

Com a ênfase dada à discussão ao decorrer do tempo, a Conferência das Nações Unidas sobre Desenvolvimento e Meio Ambiente (Rio 92) foi realizada no Rio de Janeiro, em 1992, exaltou e legitimou o conceito de desenvolvimento sustentável e, dentre os resultados, aprovou a Agenda 21, consolidando-se como um dos maiores e mais relevantes eventos políticos do século XX. A Agenda 21 é um mecanismo que planeja a idealização e construção de cidades sustentáveis, responsabilizando as nações pela garantia dos recursos para gerações futuras (MOURA; BARRETO FILHO, 2017).

Em 2015, Estados-Membros da Organização das Nações Unidas (ONU) reuniram-se em Nova lorque no sentido de dar continuidade a agenda ambiental de desenvolvimento, estabelecida no ano 2000 com prazo final em 2015, por meio dos Objetivos do Desenvolvimento do Milênio (ODM), constatando-se a necessidade de complementação (UN, 2015). Verificaram que o maior obstáculo no alcance potencial do desenvolvimento sustentável é a erradicação da pobreza em todas as suas faces. Para auxílio nessa jornada, foi elaborada a Agenda 2030 para o Desenvolvimento Sustentável, que consiste em um conjunto de 17 objetivos e 169 metas que podem ser realizadas por todas as nações de acordo com as suas devidas prioridades e recursos, até o ano de 2030.

Os Objetivos para o Desenvolvimento Sustentável (ODS) propostos na Agenda 2030 consistem em:

- $\quad$ erradicação da pobreza - acabar com a pobreza em todas as suas formas e em todos os lugares; 
- fome zero e agricultura sustentável - acabar com a fome, alcançar a segurança alimentar e melhoria da nutrição e promover a agricultura sustentável;

- saúde e bem-estar - assegurar uma vida saudável e promover o bemestar para todos, em todas as idades;

- educação de qualidade - assegurar a educação inclusiva e equitativa de qualidade e promover oportunidades de aprendizagem ao longo da vida para todos;

- igualdade de gênero - alcançar a igualdade de gênero e empoderar todas mulheres e meninas;

- água potável e saneamento básico - assegurar a disponibilidade e a gestão sustentável da água e saneamento para todos;

- energia acessível e limpa - assegurar o acesso confiável, sustentável, moderno e a preço acessível à energia para todos;

- trabalho decente e crescimento econômico - promover o crescimento econômico sustentado, inclusivo e sustentável, emprego pleno e produtivo e trabalho decente para todos;

- indústria, inovação e infraestrutura - construir infraestruturas resilientes, promover a industrialização inclusiva e sustentável e fomentar a inovação;

- redução das desigualdades - reduzir as desigualdades dentro dos países e entre eles;

- cidades e comunidades sustentáveis - tornar as cidades e os assentamentos humanos inclusivos, seguros, resilientes e sustentáveis;

- consumo e produção responsáveis - assegurar padrões de consumo e produção sustentáveis;

- ação contra a mudança global do clima - tomar medidas urgentes para combater a mudança do clima e seus impactos;

- vida na água - conservar e promover o uso sustentável dos oceanos, dos mares e dos recursos marinhos para o desenvolvimento sustentável;

- vida terrestre - proteger, recuperar e promover o uso sustentável dos ecossistemas terrestres, gerir de forma sustentável as florestas, combater a desertificação, deter e reverter à degradação da terra e deter a perda; 
- paz, justiça e instituições eficazes - promover sociedades pacíficas e inclusivas para o desenvolvimento sustentável, proporcionar o acesso à justiça para todos e construir instituições eficazes, responsáveis e inclusivas em todos os níveis;

- parcerias e meios de implementação - fortalecer os meios de implementação e revitalizar a parceria global para o desenvolvimento sustentável.

Um dos principais desafios do desenvolvimento sustentável é informar e educar pessoas sobre as suas possibilidades e necessidades, orientando-os sobre bases ecológicas, equidade social e preservação ambiental. A conexão meio ambiente e ser humano é imprescindível para o alcance dos objetivos do desenvolvimento sustentável em sua totalidade (CHIPINDO, 2018).

Citada agenda ambiental se constitui em um pacto global que, por meio de parcerias, intenciona estabelecer desenvolvimento com prosperidade e paz para todas as pessoas do Planeta, com forte promoção de direitos humanos, manutenção da qualidade ambiental e da dignidade da vida (ONU, 2015).

\subsection{Gestão para Sustentabilidade}

A partir da década de 1980, o relacionamento entre desenvolvimento sustentável e o setor de negócios começou a ser tratado com relevância, revolucionando inteiramente a conexão empresa e meio ambiente. Para Kneipp et. al (2012), as teorias econômicas convencionais não são apropriadas para liderar as empresas no futuro, já que historicamente se beneficiaram do capital natural, fomentando a sua destruição e o excluindo como fator de real relevância dentro do setor empresarial.

Kneipp et al. (2012) definem gestão sustentável como uma perspectiva de negócios que leva em consideração o padrão de organização dos ecossistemas presentes nos processos de decisão e práticas de gestão considerando pontos de avaliação econômica, ambiental e socialmente sustentáveis.

É necessária uma ação agregada das dimensões que formam o tripé da sustentabilidade, tendo em vista que a esfera econômica visa à lucratividade e o comprometimento do desenvolvimento econômico da empresa ou corporação. Em 
uma perspectiva social, o desafio é a constante busca de equidade social e, portanto, um mundo mais justo. $\mathrm{Na}$ esfera ambiental, pela própria definição anteriormente discutida de desenvolvimento sustentável, trata-se sobre a garantia de uso e proteção dos recursos atuais sem comprometer os recursos para as gerações futuras (KNEIPP et al., 2012).

Portanto, baseando-se nos conceitos de organização e gestão sustentável, o maior desafio encontrado é o equilíbrio entre poder econômico, equidade social e proteção ao meio ambiente em ações com resultados a curto e, principalmente, longo prazo. Essa integração possui capacidade revolucionária, do ponto de vista do desenvolvimento sustentável, de mudança na produção e produtos sustentáveis (KNEIPP et al., 2012).

As metas e indicadores dos ODS influenciam na formulação e execução das políticas no território, visando à criação de um ambiente favorável para a ação no nível local. É preciso localizar cada ação e as estratégias que estão sendo adaptadas, dentro de contextos específicos para as diferentes cidades e regiões (ONU, 2016). Assim, a Organização das Nações Unidas tem feito esforço importante para identificar boas práticas realizadas por diferentes atores sociais com vistas a atender às metas dos ODS.

Dentre as boas práticas identificadas que utilizam os conceitos dos ODS, por exemplo na América Latina, estão: Programa de Restauração de Suzano (regeneração da vegetação nativa brasileira); Índice de prosperidade da Cidade do México e Ação Urbana Global na cidade de Nova York (UN, 2020ª). Outras iniciativas estão dispostas também no Relatório dos Objetivos do Desenvolvimento Sustentável - 2019 (UN, 2019) e no documento "Shared responsability, global solidarity" (UN, 2020b) em que se afirma a necessidade de se removerem obstáculos para permitir uma resposta adequada ao alcance dos ODS, mesmo em tempos de pandemia.

\subsection{Geoparques e geossítios}

Segundo a UNESCO (2006), o conceito de Geopark baseia-se em:

Uma região com limites bem definidos, envolvendo um número de sítios do patrimônio geológico-paleontológico de especial importância científica, raridade ou beleza, não apenas por razões geológicas, mas também em virtude de seu valor arqueológico, ecológico, histórico e cultural. 
De acordo com a UNESCO, a criação de geoparques é objetivada pela preservação, geração e divulgação de características do patrimônio geológico, com a difusão do geoturismo, educação ambiental e viabilizando as atividades produtivas locais, enfatizando sempre a sustentabilidade nessas ações (OLIVEIRA; SILVA, 2014).

Segundo a Comissão Brasileira de Sítios Geológicos e Paleobiológicos (SIGEP), os geossítios que integram os geoparques devem estimular a pesquisa científica, propagar conhecimento e enraizar uma consciência de preservação, estimulando o crescimento social, econômico e ambiental das comunidades locais (OLIVEIRA; SILVA, 2014).

Nessa perspectiva, a geodiversidade é a integração da diversidade geológica, geomorfológica e pedológica, além dos processos que as originaram e as modelam de forma dinâmica atualmente. Deve ser conservada como parte fundamental do patrimônio cultural e geográfico e utilizada para fins científicos, didáticos e geoturísticos, aplicados nos geossítios, com base nos seus 7 (sete) valores fundamentais: intrínseco, cultural, estético, econômico, funcional, científico e didático (MOURA-FÉ et al., 2017b [2]).

Os valores científico e didático podem ser considerados como os mais relevantes para a geodiversidade, possibilitando uma segurança de informação existente para contar a história local e prevenir-se de possíveis situações de risco, entre demais aplicações existentes (MOURA-FÉ et al., 2017b[2]).

Com o avanço das comunidades e do setor econômico, a segurança da geodiversidade é ameaçada constantemente. Para reverter esse cenário de vulnerabilidade estão sendo elaboradas estratégias de conservação da geodiversidade, também conhecida como geoconservação, que busca a caracterização, preservação e gestão do patrimônio geológico e os processos naturais associados das comunidades em questão (MOURA-FÉ, 2017b[2]).

Dentre as estratégias propostas pela geoconservação, duas tomam destaque: geoturismo e geoeducação. Nesse contexto, o geoturismo pode ser classificado como uma atividade do ramo turístico, de forma integrada e organizada a lugares que possuem valor e significância histórica e/ou cultural (MOURA-FÉ, 2017b[2]). A geoeducação é um ramo científico que exalta a importância da implantação da 
educação ambiental para acontecimento da geoconservação do patrimônio cultural, e deve ser executada e fomentada por âmbitos privados e públicos (MOURA-FÉ, 2016).

\section{MÉTODO DE PESQUISA}

A pesquisa é classificada como exploratória, envolvendo levantamento bibliográfico, entrevistas com pessoas experientes no problema pesquisado. Foi desenvolvido levantamento bibliométrico em base de dados como Science Direct, Scopus e Web Knowledge, de artigos científicos atuais.

$\mathrm{Na}$ abordagem, este trabalho se classifica como uma pesquisa qualitativa, "onde a característica distintiva, em contraste com a pesquisa quantitativa, é a ênfase na perspectiva do indivíduo que está sendo estudado" (MIGUEL, 2012, p. 50).

A coleta de dados foi feita em 5 localidades: Sertãozinho (Crato), Caldas (Barbalha), Olho D'água, Pedra Branca e Sítio Gostoso (Nova Olinda), através de entrevistas estruturadas com a comunidade e gestores dos geossítios, por meio de questionário aplicado a 80 habitantes, maiores de 18 anos, utilizando a ferramenta DataScope, em que a primeira parte do formulário se constituía no Termo de Consentimento Livre e Esclarecido, garantindo-se o anonimato dos participantes; além de análise de documentos e material visual.

O documento norteador para elaboração das perguntas foi UNDD (2020) intitulado "Que és uma buena prática?" em que traz uma série de variáveis sobre participação das partes interessadas de diferentes setores, considerando que estas são também chamadas a desempenhar papéis importantes para contribuir para o alcance da Agenda 2030.

Para facilitar a realização da pesquisa na comunidade, elaborou-se um protocolo com base nos 17 Objetivos de Desenvolvimento Sustentável (ODS), consoante ONU (2016) no documento "Roteiro para a localização dos Objetivos do Desenvolvimento Sustentável: implementação e acompanhamento no nível subnacional", o qual deram subsídios às perguntas do questionário, a saber: 
Quadro 01 - Perguntas feitas à população.

OBJETIVO 01 - ERRADICAÇÂO DA POBREZA

1. Quantas pessoas moram em sua residência contando com você?

2. Quantos quartos há em casa?

3. Você trabalha?

4. Você conhece pessoas na comunidade que vivem em extrema pobreza?

OBJETIVO 02 - FOME ZERO E AGRICULTURA SUSTENTÁVEL

5. Conhece alguém que tem horta comunitária?

6. Quantas refeições você faz durante o dia?

OBJETIVO 03 - SAÚDE E BEM ESTAR

7. Você pratica alguma atividade física?

8. Tem acompanhamento médico para as pessoas da comunidade?

OBJETIVO 04 - EDUCAÇÃO DE QUALIDADE

9. Você observa a existência de algum programa na comunidade voltado para questões ambientais? OBJETIVO 05 - IGUALDADE DE GÊNERO

10. Existe capacitação das pessoas da comunidade que restringem a participação a homens ou mulheres?

11. Você observa se as mulheres têm poder de decisão e participação efetiva na comunidade?

12. Você conhece casos de violência contra mulher na comunidade?

OBJETIVO 06 - ÁGUA POTÁVEL E SANEAMENTO

13. A sua residência possui água encanada?

14. Existe algum problema na distribuição de água?

OBJETIVO 09 - INDÚSTRIA, INOVAÇÃO E INFRAESTRUTURA

15. Já participou de alguma oficina para a criação de artesanatos ou produtos caseiros?

16. Você acha que a venda desses produtos influencia o turismo da região?

OBJETIVO 11 - CIDADES E COMUNIDADES SUSTENTÁVEIS

17. Os turistas do geossítio vêm até a comunidade?

18. Se "sim", quantos turistas em média por semana?

19. Quais impactos na comunidade deixados pelos turistas?

OBJETIVO 12 - PRODUÇÃO E CONSUMO SUSTENTÁVEIS

20. Existe atividade econômica na comunidade ligada ao geossítio?

21. Caso a resposta anterior tenha sido "sim", quais são?

22. O geossítio traz alguma rentabilidade para a comunidade?

23. Existe algum tipo de reciclagem dos resíduos na comunidade?

OBJETIVO 15 - PROTEGER A VIDA SILVESTRE

24. Há caçambas de lixo nas ruas desta comunidade?

25. O caminhão do lixo passa na comunidade fazendo a coleta de lixo?

Fonte: Autoras (2021).

Foi realizado estudo de campo, através de 10 visitas in loco, no período de agosto a setembro de 2020, para análise de informações da realidade encontrada. A análise dos resultados dos questionários permitiu identificar as dimensões que precisam ser trabalhadas para o alcance da sustentabilidade nos geossítios em questão e diagnosticar os pontos fracos e fortes para que este objetivo seja alcançado.

O diagnóstico dos pontos fracos e fortes, quanto às comunidades, foi realizado por meio da utilização do método SWOT. Conforme Sales-Maciel (2020) a metodologia SWOT é uma matriz com acrônimo das palavras inglesas Strengths, Weaknesses, Opportunities e Threats, que pode ser utilizada para auxiliar como ferramenta estratégica na identificação das variáveis de Forças, Fraquezas, 
Oportunidades e Ameaças, respectivamente, que influenciam na competitividade de uma organização (XAVIER, 2017; MOREIRA, 2017).

As respostas fornecidas pelos entrevistados às perguntas do Quadro 01 foram estudadas e em concordância com estas, pôde-se incorporá-las na matriz SWOT em busca de reconhecer e verificar as forças, fraquezas, oportunidades e ameaças existentes nas comunidades. Assim, possibilitando um olhar específico sobre os pontos que devem ser reconhecidos e melhorados de acordo com os ODS que podem ser vistos em ação nas comunidades, apontando formas viáveis de trabalhá-los e advertindo sobre circunstâncias que podem ser comumente encontradas na busca da sustentabilidade.

\section{ESTUDO DE CASO GEOPARK ARARIPE}

Criado no ano de 2006, o Geopark Araripe é o primeiro geoparque das Américas e do hemisfério Sul com selo da UNESCO e um dos componentes da Rede Global de Geoparques (Global Geoparks Network - GGN). O Geopark Araripe situase no sul do estado do Ceará, na bacia sedimentar do Araripe. O Geopark Araripe possui hoje 9 (nove) geossítios abertos para visitação e com alta capacidade de crescimento e desenvolvimento, e 57 (dezessete) geossítios identificados, que não estão inventariados ainda e, por conservação e precaução, também não estão abertos à visitação (MOURA-FÉ, 2016), englobando 6 (seis) municípios: Juazeiro do Norte, Crato, Barbalha, Missão Velha, Santana do Cariri e Nova Olinda.

A região do Cariri cearense, onde está localizado o Geopark Araripe, possui notável geodiversidade relacionada diretamente a sua biodiversidade e cultura locais, sob expressões materiais e imateriais, proporcionando o avanço do geoturismo e gerando espaço para atividades relacionadas à geoeducação, potencializando um processo de cuidado e orgulho do patrimônio cultural pelo morador local e instaurando estratégias de preservação ambiental (MOURA-FÉ, 2017a[1]).

O geoturismo e a geoeducação possuem potencial de aplicação, no contexto Geopark Araripe, nos geossítios abertos para a visitação pública, a saber:

- geossítio Colina do Horto (Juazeiro do Norte) - localizado a $3 \mathrm{~km}$ da sede da cidade de Juazeiro do Norte, em que se destaca a estátua do Padre Cícero, o Museu Vivo do Padre Cícero, a Igreja do Bom Jesus do Horto e a trilha de 
acesso ao Santo Sepulcro. Possui inestimável valor histórico, cultural e espiritual;

- geossítio Riacho do Meio (Barbalha) - oferece trilhas e bicas de água, contempla lugares como a Pedra do Morcego, o Balneário do Caldas, dentre outros. Em meio ao ecossistema ao qual está inserido, destaca-se pela presença da espécie de ave Soldadinho do Araripe, criticamente em perigo de extinção, e pela formação de arenitos;

- geossítio Floresta Petrificada (Missão Velha) - localizado no Sítio Olho D’Água Comprido. O geossítio é portador de um valor paleontológico imensurável, com especial importância para o estudo da paleobotânica e evolução geológica;

- geossítio Cachoeira de Missão Velha (Missão Velha) - caracteriza-se por quedas de água de até 12 metros de altura, banhadas pelas águas do rio Salgado. Possui valor científico, cultural e social;

- geossítio Pedra Cariri (Nova Olinda) - compreende uma antiga área de mineração de calcário conhecida por Mina Triunfo. Possui valor social, cultural e histórico;

- geossítio Ponte de Pedra (Nova Olinda) - corresponde a uma geoforma esculpida no arenito, resultado da erosão provocada pela água ao longo dos últimos milhões de anos;

- geossítio Parque dos Pterossauros (Santana do Cariri) - são realizadas escavações paleontológicas em rochas, em busca de concreções calcárias que geralmente possuem fósseis. Possui um valor científico-didático incalculável;

- geossítio Pontal da Santa Cruz (Santana do Cariri) - localizado na estrada que dá acesso ao topo da Chapada do Araripe. Possui trilhas estimadas por turistas e aventureiros locais, tornando-se um ponto turístico essencial da região do Cariri;

- geossítio Batateiras (Crato) - localizado no Parque Estadual Sítio Fundão, sua nascente guarda histórias e lendas indígenas. O lugar é rodeado por trilhas ecológicas.

Estes geossítios são responsáveis pelas maiores belezas da região e recebem diversos tipos de turistas em diferentes épocas do ano. Além de serem Revista Produção Online. Florianópolis, SC, v. 21, n. 3, p. 973-999, 2021 
representações expressivas da biodiversidade da região do Cariri cearense que é diretamente conectada a elementos da cultura, expressando-se de forma material ou imaterial, estruturando significativamente a história da região (MOURA-FÉ, 2016).

Para além do valor histórico e cultural, os geossítios do Geopark Araripe da UNESCO possuem notável importância no turismo e, consequentemente, no avanço econômico da região e das comunidades ao seu redor. O turismo, por sua vez, é transformador e possui iniciativas que fomentam o seu acontecimento a partir da harmonia entre este, a conservação do meio ambiente e a identificação sociocultural em busca da valorização regional (OLIVEIRA, 2017).

\subsection{Resultados da percepção das comunidades em relação aos ODS}

Com base na aplicação dos questionários aos residentes nas 5 comunidades, obtiveram-se os seguintes resultados em relação aos 17 Objetivos do Desenvolvimento Sustentável. Estão aqui apresentados aqueles com maior interface com a realidade das comunidades em questão.

Apesar de cada região possuir peculiaridades que as tornam únicas, conseguese enxergar semelhanças entre elas quando se trata do nível de sustentabilidade e a busca para atingi-la. Com isso em mente, as perguntas elaboradas possuíam caráter de impacto amplo, levando em consideração fatores que afetassem o dia a dia de todas as comunidades e sua jornada em busca da sustentabilidade, seja de forma perceptível ou não.

Para mensurar o ODS 01 (Erradicação da Pobreza), foram realizadas 04 perguntas, a saber: P1: "Quantas pessoas moram em sua residência contando com você?", P2 "Quantos quartos têm em sua casa?", P3 "Você trabalha?" e P4"Você conhece pessoas na comunidade que vivem em extrema pobreza?".

Por meio da Figura 1, é possível perceber na resposta à quarta questão a maior preocupação com Objetivo do Desenvolvimento Sustentável (ODS1), onde obteve-se que a única comunidade que atendeu o requisito estabelecido foi o Sertãozinho, em que os entrevistados relatam que não possuem conhecimento de pessoas em situação de extrema pobreza. Entretanto, o índice de desemprego ainda é alarmante nesta região causando, assim, um contrapeso com a questão de pessoas em situação de pobreza. 


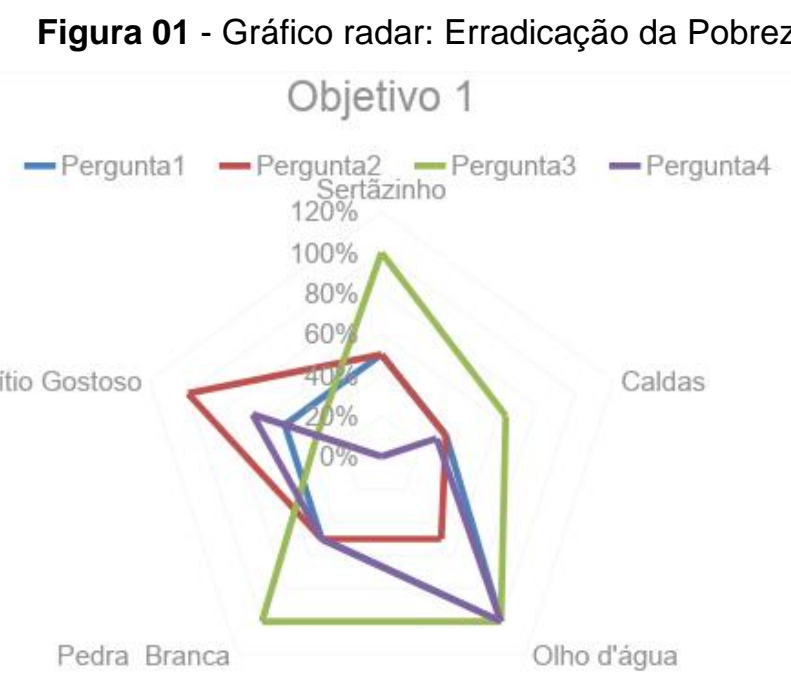

Fonte: Autoras (2021)

Destaca-se, ainda, que os resultados para a comunidade Olho D'água retratam que $100 \%$ dos entrevistados conhecem pessoas em situação de extrema pobreza.

A figura 2 diz respeito à percepção das 5 comunidades com relação ao ODS 2 , em que duas questões foram analisadas, sendo essas: P5 - a existência de hortas nas comunidades e P6 - a quantidade de refeições feitas durante o dia.

Figura 02 - Gráfico radar: Fome Zero e Agricultura Sustentável

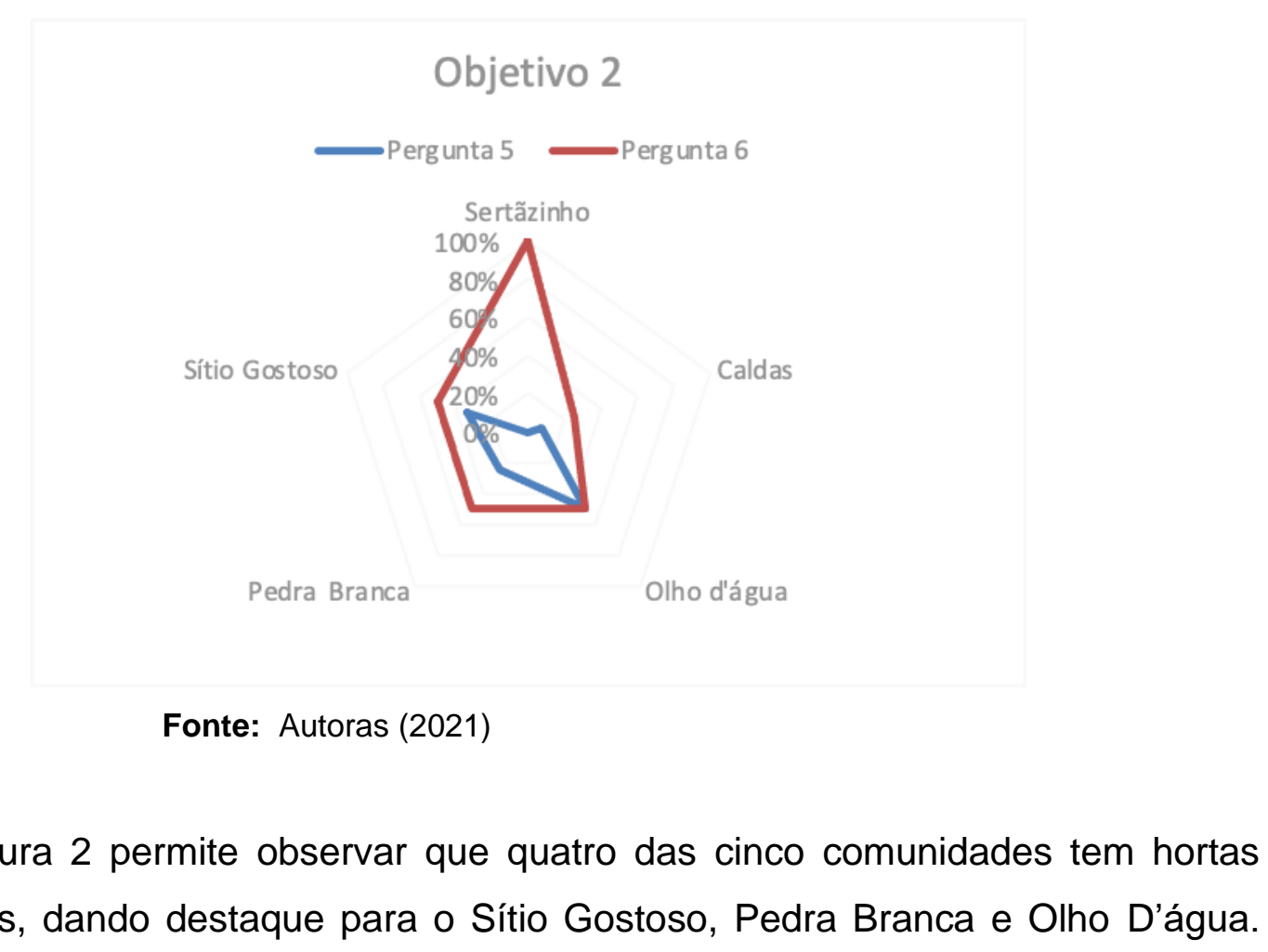

comunitárias, dando destaque para o Sítio Gostoso, Pedra Branca e Olho D’água. 
Quanto à pergunta 6, sobre quantidade de refeições, as comunidades Sertãozinho, Olho D'água, Pedra Branca e Sítio Gostoso informaram consumir acima de duas refeições diárias. Depreende-se que as comunidades Sítio Gostoso, Olho D'água e Pedra Branca aproximam-se do atendimento ao ODS 2. Nas visitas in loco realizadas durante o ano de 2020 não foram observados pedintes nas suas ruas.

A meta 2.4 (garantir alimentos e garantir práticas agrícolas sustentáveis) tem relação direta com o objetivo principal da Agenda 2030 que é a Erradicação da Pobreza. A análise dos dados permite inferir que as localidades estudadas possuem destaque neste requisito, considerando-se suas práticas em hortas comunitárias.

A figura 3 mostra os resultados dos questionamentos: P7 - prática de atividades físicas por parte dos moradores e P8 - existência de acompanhamento médico na comunidade, em relação ao ODS3 (Saúde e bem estar).

Figura 03 - Gráfico radar: Saúde e Bem-estar

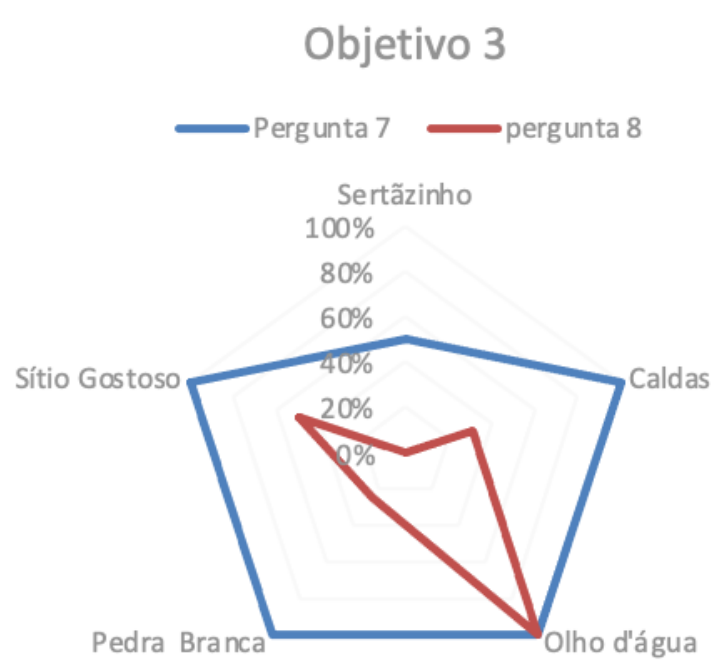

Fonte: Autoras (2021)

A figura 3 demonstra que $100 \%$ das pessoas entrevistadas do Sítio Gostoso e da comunidade Olho d'água praticam algum tipo de atividade física, $50 \%$ não praticam no Sertãozinho e $25 \%$ na Pedra Banca não tem o hábito de se exercitar. De acordo com a população entrevistada, na comunidade Sertãozinho, não existe acompanhamento médico na comunidade. Assim, contatou-se que as comunidades de Sítio Gostoso, Olho D'água, Caldas e Pedra Branca atendem aos parâmetros 
analisados em relação ao ODS 3. $\mathrm{Na}$ análise in loco observou-se que existem postos de saúde para atender a população destas comunidades.

Quanto ao ODS 4 (Educação de Qualidade), apenas uma questão foi perguntada sobre a existência ou não de escolas com desenvolvimento de programas sobre questões ambientais, cujas respostas das 5 comunidades estão na Figura 4.

Figura 04 - Gráfico radar: Educação de Qualidade

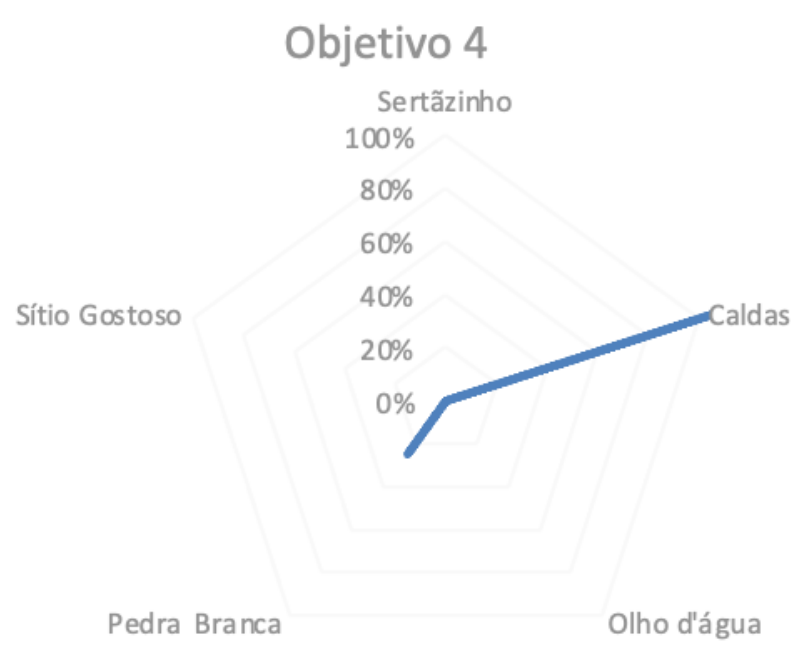

Fonte: Autoras (2021)

As comunidades Caldas e Pedra Branca possuem programas de trato das questões ambientais. As demais comunidades não possuem projetos voltados a educação ambiental para os moradores. Seria importante a existência de programas educacionais para a população no sentido de ampliarem o seu entendimento e, consequentemente, suas ações com práticas voltadas à sustentabilidade.

Apenas a comunidade do Caldas tem escola para sua população e realiza ações de preservação cultural de festejos tradicionais, com isto, aproxima-se do atendimento da meta 4.3 do ODS 4, que estabelece garantir aos alunos a aquisição do conhecimento e de habilidades para a promoção do desenvolvimento sustentável.

Com relação ao ODS 5 (Igualdade de Gênero) foram questionadas três perguntas, a saber: P11- existem capacitações de pessoas da comunidade que restringem a participação de homens ou mulheres; P12 - indaga sobre a participação das mulheres e poder de decisão e a P13 - sobre casos de violência contra a mulher. A Figura 5 mostra os resultados. 
Figura 05 - Gráfico radar: Igualdade de Gênero

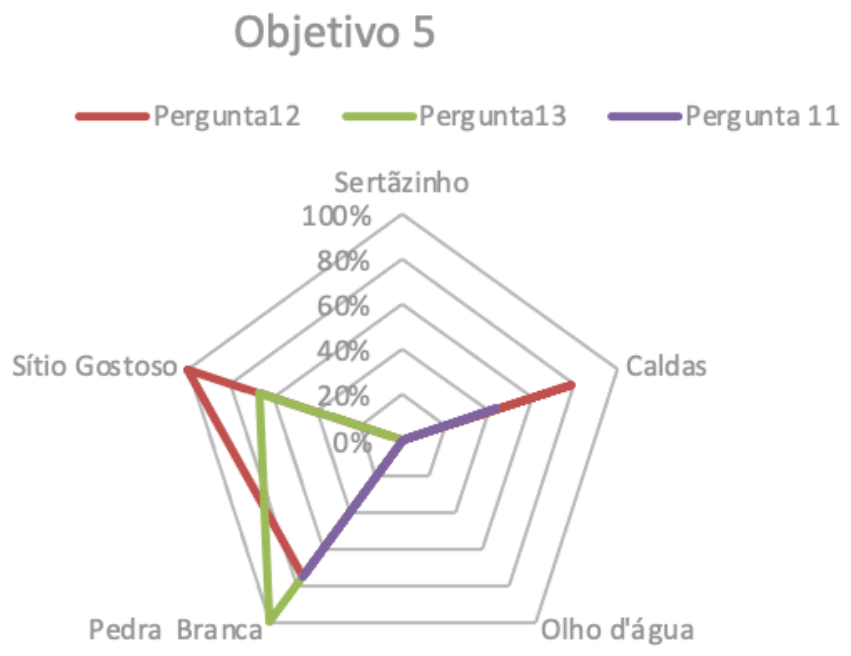

Fonte: Autoras (2021)

De acordo com as entrevistas realizadas, apenas em duas comunidades existem capacitações de pessoas da comunidade que restringem a participação de homens ou mulheres, que são as localidades do Caldas e da Pedra Branca.

Sobre a participação das mulheres, obteve-se que no Sítio Gostoso, Pedra Branca e na comunidade do Caldas as mulheres possuem poder de decisão e participação na comunidade. Quanto ao terceiro questionamento, apenas nas comunidades Sertãozinho e Olho D'água se desconhecem casos de violência contra mulher. Com isto, observa-se a necessidade de ações que visem a atender as metas do ODS 5, a exemplo da meta 5.1, que traz a importância de eliminar todas as formas de discriminação contra as mulheres e a meta 5.2, que afirma a relevância de extinguir todas as formas de violência contra elas.

Na comunidade Pedra Branca, 100\% dos entrevistados afirmam conhecerem casos de violência contra a mulher. Nas comunidades Sertãozinho e Olho D'água as mulheres não têm poder de participação e decisão nas atividades da comunidade. Esses dados ilustram a insuficiência do atendimento do ODS 5 e que é preciso desenvolver projetos de empoderamento e liderança feminina em comunidades, principalmente, interioranas.

Quanto ao ODS 6 (Água potável e saneamento) foram duas indagações: P 14 - sobre a posse de água encanada nas casas dos moradores e P 15 - sobre a existência de problemas na distribuição de água, cujas respostas estão na Figura 6 . 
Figura 06 - Gráfico radar: Água Potável e Saneamento

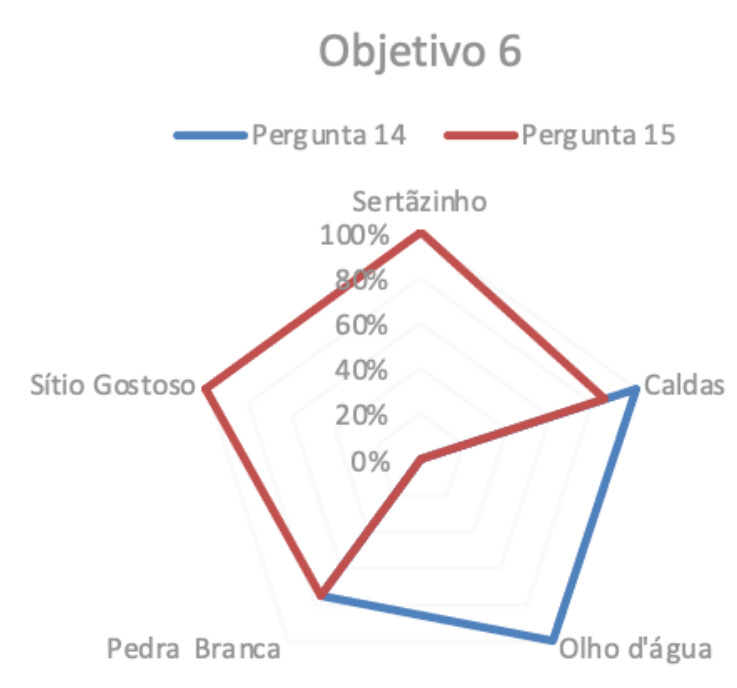

Fonte: Autoras (2021)

Na primeira pergunta, três das cinco comunidades têm água encanada, são estas Caldas, Olho D'Água e Pedra Branca. Porém, a comunidade de Caldas e de Pedra Branca apresentam grandes problemas com a distribuição de água. Com isto, apenas a comunidade Olho D'água atendeu o requisito $100 \%$.

Por tratar-se de um fator que é indispensável no dia a dia e que tem também previsão legal consoante a Política Nacional e a Estadual de Saneamento Básico, é preocupante identificar que apenas 1 (uma) das 5 (cinco) comunidades atendeu a ambas as perguntas, aproximando-se das metas 6.1 (acesso universal de água) e 6.2 (acesso a adequados serviços de esgotamento) do ODS 6. Mesmo sendo imprescindível o acesso à água potável de qualidade e ao esgotamento sanitário, principalmente na prevenção de doenças, pode-se perceber que existe uma deficiência significativa nas comunidades estudadas e que precisa melhor investimento por parte dos titulares da prestação de serviços de saneamento a fim de alcançar não apenas a sustentabilidade adequada, mas também qualidade de vida para a população.

Consoante o ODS 9 (Indústria, Inovação e Infraestrutura), duas perguntas foram estabelecidas para identificação de pequenos produtores. A primeira pergunta - "Já participou de alguma oficina para a criação de artesanatos ou produtos caseiros?". Na segunda, questiona-se a opinião da população sobre a influência dos produtos no turismo da região (Ver figura 7).

Revista Produção Online. Florianópolis, SC, v. 21, n. 3, p. 973-999, 2021 
Figura 07 - Gráfico radar: Indústria, Inovação e Infraestrutura

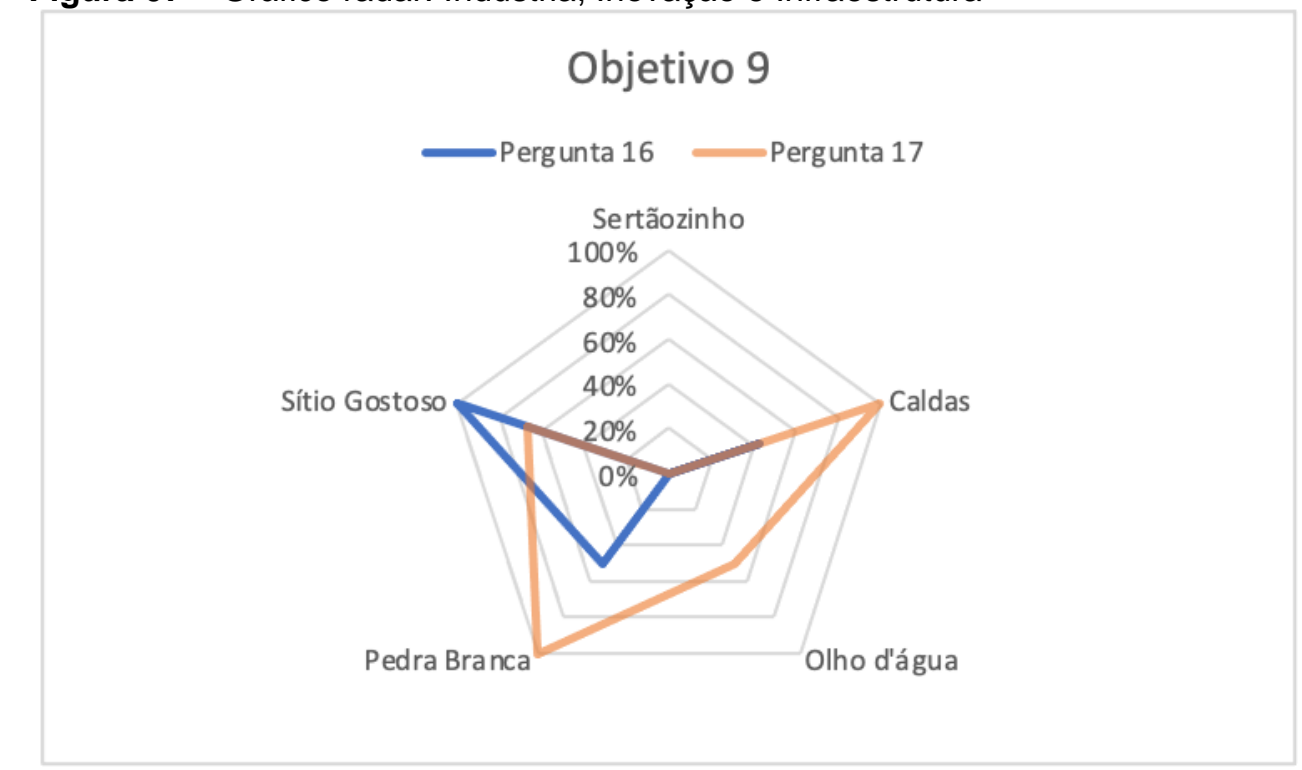

Fonte: Autoras (2021)

Três comunidades responderam ter participação da população em oficinas de artesanato ou produtos caseiros, estas são as comunidades Caldas, Pedra Branca e Sítio Gostoso. Quanto à segunda questão, quatro comunidades consideram que os produtos influenciam no turismo da região.

Nas visitas realizadas foi possível observar os produtos que possuem referenciação ao geossítio que a comunidade está inserida ou ao próprio Geopark Araripe da UNESCO (conhecidos como geoprodutos, pelo seu caráter de identificação cultural e regional), entre esses podem-se citar remédios caseiros, artesanatos, confecção de roupas, entalhamento de madeira, dentre outros.

Esses produtos são de grande importância para a expansão e propagação do Geopark Araripe e da cultura regional, chegando em espaços e pessoas de forma muito próxima, abrindo oportunidade para uma nova visitação. Os geoprodutos também ocasionam impacto emocional no turista, possibilitando o desejo de reviver a visita.

Concernente ao ODS 11, que trata sobre cidades e comunidades sustentáveis, foi perguntado se os turistas vão até as localidades estudadas (ver figura 8). 
Figura 08 - Gráfico radar: Cidades e Comunidades Sustentáveis

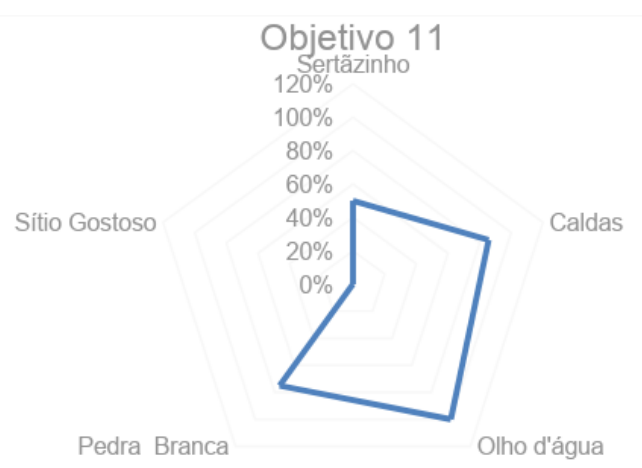

Fonte: Autoras (2021)

Quatro das 5 (cinco) comunidades informaram que os turistas frequentam o local, são estas Sertãozinho com 50\%, Caldas com 85,7\%, Olho D'água com $100 \%$ e Pedra Branca com 75\%.

$\mathrm{Na}$ Pedra Branca, a população informou que os visitantes chegam em ônibus com lotação máxima até os pontos de visitação. As outras localidades não souberam informar de que maneira os turistas viajam. As comunidades que informaram que recebem turistas relataram que um dos principais efeitos resultantes da visitação é o lixo gerado.

A comunidade Caldas recebe cerca de 3.840 turistas por semana, esta é uma região com maior estrutura turística. Com variados pontos turísticos, trilhas ecológicas, pousadas, o popular balneário, entre outros, a região consolida um mercado turístico de grande importância regional, atraindo diversos tipos de turistas. Os moradores que vivenciam o turismo diariamente relatam que um dos principais impactos positivos é o aumento na movimentação econômica local.

A figura 9 trata do ODS 12 (Consumo Responsável) e, com base nele, foram feitas quatro perguntas, a saber: P 21 - existem atividades econômicas ligadas ao geossítio?, P 22 - caso sim, quais são?, P 23 - o geossítio traz rentabilidade para comunidade?, P 24 - Existe reciclagem de resíduos sólidos? 
Figura 09 - Gráfico radar: Consumo Responsável

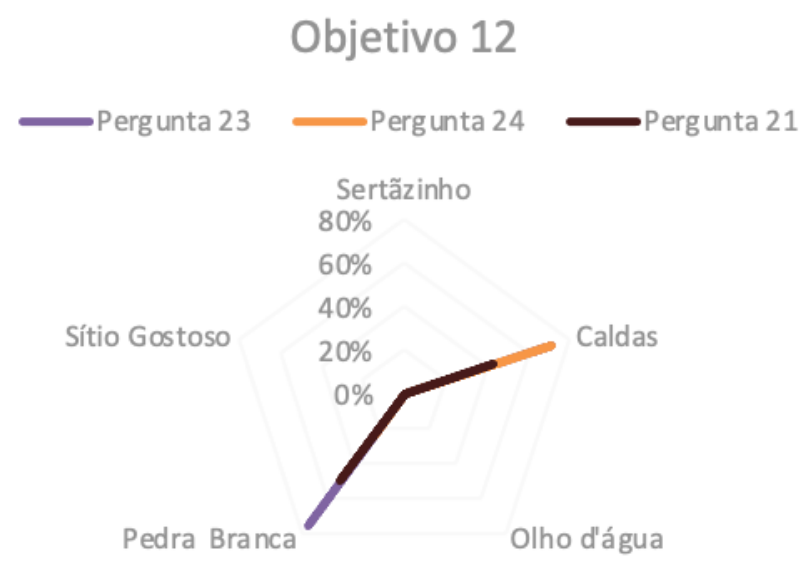

Fonte: Autoras (2021)

$\mathrm{Na}$ primeira questão, apenas duas comunidades das cinco pesquisadas apresentam atividades econômicas ligadas ao geossítio, que são o Caldas e a Pedra Branca. No Caldas, como anteriormente citado, existem trilhas ecológicas, balneários, e ainda a partir de observações feitas in loco, identificou-se também a existência de produtos de artesanato que referenciam o Araripe Geopark Mundial da UNESCO.

$\mathrm{Na}$ comunidade Pedra Branca existe a extração da Pedra Cariri, maior representação do geossítio, pois são encontrados diversos fósseis, além da beleza única dessa pedra. Entretanto, apenas estas duas comunidades relataram que o geossítio traz rentabilidade direta para a população.

Os moradores do Caldas e da Pedra Branca relataram que existe reciclagem de resíduos sólidos na comunidade. Na localidade do Caldas, existe reciclagem dos resíduos e transformação em artesanatos, como também, segundo relatos dos moradores, algumas pessoas passam semanalmente nas ruas recolhendo resíduos recicláveis. Na comunidade da Pedra Branca, os respondentes afirmaram que alguns moradores reutilizam os resíduos da mineração da Pedra Cariri.

Em relação ao ODS 15 (Vida sobre a Terra), duas questões foram feitas: P 25 - existe coletor de resíduos sólidos? e P 26 - existem ações de proteção dos recursos ambientais? As respostas podem ser vistas na Figura 10. 
Figura 10 - Gráfico radar: Proteger a vida silvestre.

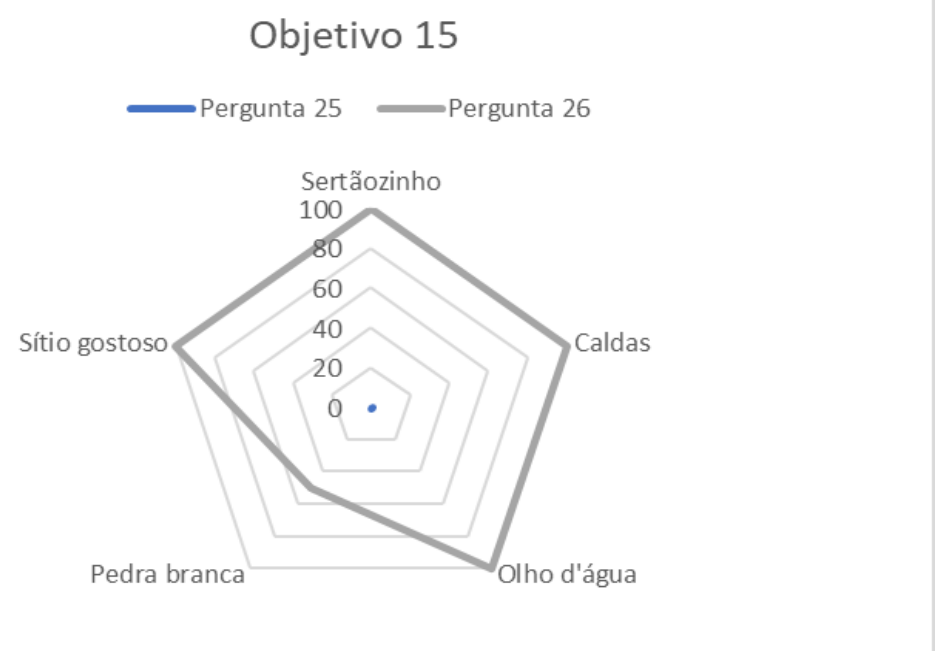

Fonte: Autoras (2021).

Apenas a comunidade do Caldas identificou a existência de caçamba de lixo nas ruas da localidade, conforme figura 10. Entretanto, em todas as comunidades caminhões do serviço público fazem a coleta de lixo, mas em dias distintos e em períodos diferenciados, por exemplo, em alguns lugares o serviço de coleta passa a cada 15 dias e em outras passa mais de uma vez durante a semana. Nas observações das visitas in loco, constatou-se que na comunidade Pedra Branca existem alguns pontos com lixos nas ruas.

A comunidade Caldas teve um destaque relacionado ao ODS 15, pela constatação de conscientização da população em relação à proteção ambiental. As ruas têm placas informativas e o local tem ações de conscientização ambiental, dentre outras práticas afeitas à conservação dos recursos naturais. Também foi informado que existe uma ação anual de reflorestamento na comunidade, observou-se também a existência de lixeiras nas ruas, porém em algumas faltam manutenções.

\subsection{Resultados da análise SWOT}

A partir da seleção dos Objetivos do Desenvolvimento Sustentável (ODS) que melhor se encaixaram na realidade das comunidades que compõem os geossítios do Geopark Araripe, ou seja os ODS 1, 2, 3, 4, 5, 6, 8, 9, 11, 12 e 15, realizou-se análise mais estruturada da realidade existente nesses locais, por meio de Análise SWOT objetivando diagnóstico mais completo. 
A análise SWOT é uma ferramenta que auxilia no desenvolvimento estratégico de empresas. Aqui ela possui a função de melhorar a percepção dos pesquisadores dos fatores envolvidos que foram coletados e analisados a partir dos relatos concedidos pelos moradores das 5 comunidades estudadas.

Quadro 02 - Análise SWOT da percepção dos moradores de 5 comunidades no UNESCO Geopark Araripe

\begin{tabular}{|l|l|}
\hline \multicolumn{1}{|c|}{ FORÇAS (STRENGTHS) } & \multicolumn{1}{c|}{ FRAQUEZAS (WEAKNESSES) } \\
A extrema pobreza não é uma realidade & Inexistem programas educacionais voltados \\
presente nestas comunidades. As casas são & para a proteção ambiental \\
simples, com manutenção e com boa & As associações não estão estabelecidas na \\
higiene, em sua maioria. & maioria das comunidades \\
As comunidades possuem um baixo índice & Existem comunidades sem água encanada e \\
de desemprego. & esgotamento sanitário. \\
Inexiste fome nestas comunidades. & O índice alarmante de desemprego de uma \\
Há atendimento médico em postos de saúde & das comunidades é crítico \\
locais. & Há comunidades com dados preocupantes \\
Os Índices de prática de atividades físicas & de violência contra a mulher. \\
são satisfatórios. & A maioria das comunidades não possui \\
Em três das comunidades não se & trabalhos/ações de coleta seletiva ou \\
observaram problemas relacionados a & reciclagem. \\
restrições de gênero. & \\
A maioria das comunidades estudas & \\
desenvolvem Geoprodutos e mesmo a que & \\
não trabalha diretamente com isso percebe a & \\
importância deste para o turismo regional. & \\
As comunidades já estão sendo procuradas & \\
e visitadas por um grande número de & \\
visitantes e isso movimenta a economia & \\
local. & \\
Há em todas as comunidades uma & \\
preocupação com a coleta de lixo. &
\end{tabular}

\section{OPORTUNIDADES (OPPORTUNITIES)}

Comunidades buscam instalar hortas comunitárias.

Há espaço para implementação de novos espaços de práticas de atividade física nas comunidades.

Existem programas voltados para questões ambientais em fase inicial, podendo ser ampliado.

Oportunidades para o desenvolvimento de programas ou oficinas de:

- empoderamento feminino.

- artesanatos e produtos caseiros.

- coleta seletiva.

- reciclagem.

Atividades relacionadas aos geossítios.

\section{AMEAÇAS (THREATS)}

A quantidade de resíduos sólidos deixados pelos turistas.

O desconhecimento sobre Geopark, geoturismo e suas potencialidades para crescimento sustentável.

O desconhecimento sobre desenvolvimento sustentável e suas soluções para melhoria da qualidade de vida.

Fonte: Autoras (2021) 
A partir da análise, pode-se perceber que as comunidades estudadas possuem pontos fortes muito solidificados e em contraponto fraquezas que podem ser trabalhadas e transformadas em oportunidades de mudança e desenvolvimento.

Pela forma como os dados estão distribuídos na análise realizada, é perceptível que há facilidade e uma visão clara dos pontos em destaque e das oportunidades para a aplicação de projetos e iniciativas a fim do alcance da sustentabilidade nas regiões que foram estudadas.

Mesmo com as ameaças existentes que podem prejudicar as comunidades e o seu crescimento para a sustentabilidade, é notável que, assim como a região em que estão inseridos, os moradores, que são os maiores instrumentos de mudança, possuem resiliência e força para vencer todas as adversidades.

Com isso, pode-se observar que as regiões em destaque possuem pontos de grande significância para o cumprimento dos Objetivos do Desenvolvimento Sustentável propostos pela ONU. Entretanto, ainda existe espaço e oportunidades de crescimento e ampliação da sustentabilidade nos geossítios e comunidades ao redor do Geopark Araripe da UNESCO, fazendo destas áreas, locais de destaque para implementação da Agenda 2030 para o Desenvolvimento Sustentável e instrumentos para alcançar a mudança necessária.

\section{CONSIDERAÇÕES FINAIS}

O cenário atual vivido decorrente da pandemia da COVID-19 impossibilitou a visitação aos 9 geossítios abertos à visitação que integram o Geopark Araripe, porém os resultados obtidos nas pesquisas realizadas nos 05 (cinco) geossítios possibilitaram um levantamento importante desta pesquisa.

Infere-se, com base nos resultados obtidos, que algumas comunidades - como - Caldas - estão um passo à frente em relação às outras, porém podem-se observar dificuldades quanto à gestão sustentável em todos os geossítios analisados, reforçando a necessidade e importância do diagnóstico obtido para a elaboração de futuros projetos nas comunidades.

O diagnóstico em relação aos demais geossítios está em execução e são esperados resultados ligados com uma possível elaboração de diretrizes que podem ser utilizadas como base para gestão sustentável do território do Geopark Araripe da UNESCO e, até mesmo, estender-se para os demais. Outro resultado esperado é que 
este estudo sirva como fonte de apoio para outros trabalhos sobre o mesmo tema e acredita-se no impacto científico e técnico que o mesmo possui, já que a pesquisa é fundamentada por pesquisas de campo e pelo referencial teórico robusto.

Para além disso, reforça-se o impacto que os Objetivos do Desenvolvimento Sustentável e a Agenda 2030 possuem no alcance da sustentabilidade e aumento da qualidade de vida nas comunidades em torno dos geossítios. Pode-se afirmar que estes são os objetos de partida para uma real mudança na forma como se olha a sustentabilidade em regiões como a do Araripe Geopark Mundial da UNESCO, que podem fornecer o aparato necessário para o entendimento das situações existentes e a tomada de decisões, a partir do diagnóstico do nível de sustentabilidade, possibilitando uma mudança real nas comunidades e no mundo.

A gestão dos espaços dos geossítios se constitui em desafio alinhado à agenda ambiental das Nações Unidas e ao compromisso do atendimento das metas nacionais dos ODS.

\section{REFERÊNCIAS}

BIERMANN, Frank; KANIE, Norichika; KIM, Rakhyun E. Global governance by goalsetting: the novel approach of the UN Sustainable Development Goals. Current Opinion in Environmental Sustainability, v. 26-27, p. 26-31, 2017. https://doi.org/10.1016/i.cosust.2017.01.010

CHIPINDO, Pedro. A educação ambiental e o desenvolvimento sustentável. Revista Órbita Pedagógica, Angola, p. 51-62, 2018.

IPEA - Instituto de Pesquisa Econômica Aplicada. Agenda 2030 Objetivos do Desenvolvimento Sustentável: proposta de metas Brasileiras. Brasília: IPEA, 2018.

KNEIPP et. al. Gestão para a sustentabilidade em empresas do setor mineral. Revista de Ciências da Administração, v. 14, n. 33, p. 52-67, 2012. https://doi.org/10.5007/2175-8077.2012v14n33p52

MENEZES, Patrícia M. (org). Relatório final do 3e encontro nacional da rede ODS Brasil. Brasília, 2018. Disponível em: http://repositorio.enap.gov. br/handle/1/3249. Acesso em: 18 maio 2021.

MIGUEL, Paulo Augusto Cauchick. Metodologia de pesquisa em engenharia de produção e gestão de operações. 2. ed. Rio de Janeiro: Elsevier, 2012.

MOREIRA, R. de A. Avaliação ambiental estratégica como instrumento de Planejamento: subsídios à proposta para regulamentação no Brasil. 2017. 71 f. 
Dissertação (Mestrado) - Mestrado em Tecnologia e Gestão Ambiental, Instituto Federal do Ceará, Fortaleza, 2017.

MOURA, R.S.C.; BARRETO FILHO, B.F. Políticas púbicas para a promoção do desenvolvimento sustentável na cidade de Rafael Fernandes - RN. GeoTemas, Pau dos Ferros, Rio Grande do Norte, v. 7, n. 2, p. 17-44, jul./dez. 2017.

https://doi.org/10.33237/geotemas.v7i2.2079

MOURA-FÉ, M. M. GeoPark Araripe e a geodiversidade do sul do Estado do Ceará, Brasil. Revista de Geociências do Nordeste, v. 2, n. 1, p.28-37, 2016.

MOURA-FÉ, M.M.; SILVA, J.V.M.; BRASIL, J.G. Geocultura: proposta de estudo entre geodiversidade e cultura. Campinas: Instituto de Geociências/UNICAMP, 2017a. https://doi.org/10.20396/sbgfa.v1i2017.1954

MOURA-FÉ, M.M.; NASCIMENTO, R.L.; SOARES, L.N. Geoeducação: princípios teóricos e bases legais. Campinas: Instituto de Geociências - UNICAMP. 2017b. https://doi.org/10.20396/sbgfa.v1i2017.1953

OLIVEIRA, T.R.C. Identificação e análise dos fatores críticos para implantação de negócios hoteleiros sustentáveis na APA Chapada do Araripe.

Guaratinguetá: Universidade Estadual Paulista - UNESP, 2017.

OLIVEIRA, M.D.; SILVA, L.F. Estratégias para o fortalecimento do geoturismo no atrativo turístico Gruta do Lago Azul, Bonito (MS). Revista Turismo - Visão e Ação - Eletrônica, v. 16, n. 3, set./dez. 2014. https://doi.org/10.14210/rtva.v16n3.p629

ONU - Organização das Nações Unidas. Roteiro para a localização dos Objetivos do Desenvolvimento Sustentável: implementação e acompanhamento no nível subnacional. Brasília: ONU-BR, 2016.

ONU - Organização das Nações Unidas. Transformando nosso mundo: a agenda 2030 para o desenvolvimento sustentável. Nova lorque: ONU, 2015. Disponível em: https://sustainabledevelopment.un.org/post2015/transformingourworld/publication. Acesso em: 27 fev. 2020.

SALES-MACIEL, E. A. IPTU ecológico como instrumento econômico para a gestão ambiental do município do Eusébio-CE. 2020. 82f. Dissertação (Mestrado) - Mestrado em Tecnologia e Gestão Ambiental, Instituto Federal do Ceará, Fortaleza, 2020.

SANTOS, V.M.N.; JACOBI, P.R. Educação, ambiente e aprendizagem social: metodologias participativas para geoconservação e sustentabilidade. Rev. Bras. Estud. Pedagog., Brasília, v. 98, n. 249, p. 522-539, maio/ago. 2017. https://doi.org/10.24109/2176-6681.rbep.98i249.2758

UN - United Nations - Report of the world commission on environment and development: Our Common Future. New York: United Nations, 1987. 
UN - United Nations. The sustainable development goals report 2019. Nova York: Department of Economic and Social Affair, 2019.

UN - United Nations. SDG good practices - a compilation of success stories and lessons learned in SDG implementation. Nova York: Department of Economic and Social Affairs, 2020a.

UN - United Nations. Shared responsability, global solidarity - responding to the socio-economic impacts of COVID-19. Nova York: Department of Economic and Social Affairs, 2020b.

UNDP - United Nations Development Program. Qué és uma buena práctica? Marco para analizar la calidad de participación de las partes interesadas em la ejecución y el seguimiento de la Agenda 2030. Nova York: Departamento de Asuntos Económicos y Sociales, 2020.

UNESCO. Guidelines and criteria for national geoparks seeking unesco's assistance to join the global geoparks network, 2006.

VILHA, A.P.M.; QUADROS, R. Gestão da Inovação sob a perspectiva do desenvolvimento sustentável. Revista de Administração e Inovação, São Paulo, v. 9, n.3, p. 28-52, jul./set. 2012. https://doi.org/10.5773/rai.v9i3.593

XAVIER, A. F. Proposta de um modelo de maturidade para avaliação das práticas de ecoinovação nas organizações: Eco-Mi. 2017. 288f. Tese (Doutorado em Engenharia de Produção) - COPPE, Universidade Federal do Rio de Janeiro, Rio de Janeiro, 2017.

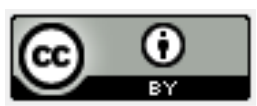

Artigo recebido em: 31/05/2021 e aceito para publicação em: 15/07/2021 DOI: https://doi.org/10.14488/1676-1901.v2113.4345 